\title{
Creative Vision and Creative Arts: Significations and Metaphors of Keys in Alex Idoko's Symbolist Arts
}

\author{
Ekenechukwu A. Anikpe1, Ndubuisi Nnanna², Adebowale O. Adeogun ${ }^{3}$ \& Emeka Aniago ${ }^{4}$ \\ ${ }^{1}$ Lecturer, Dept. of Fine \& Applied Arts, University of Nigeria, Nsukka, Nigeria \\ ${ }^{2}$ Lecturer, Dept. of Theatre \& Film Studies, University of Nigeria, Nsukka, Nigeria \\ ${ }^{3}$ Senior Lecturer, Music, University of Nigeria, Nsukka, Nigeria \\ ${ }^{4}$ Senior Lecturer, Theatre \& Film Studies, University of Nigeria, Nsukka, Nigeria \\ ORCID iD: 0000-0003-3194-1463. Email: emekaaniago@gmail.com
}

\begin{abstract}
Artistic symbols in many ways act as complimentary narrative tools that elevate and define the message from the artist, which can help to generate efficacious consciousness and mood aggregation in the beholders. The purpose of this study is to deepen the appreciation of the embedded significances of keys as symbolic objects in selected symbolist art by Alex Idoko which represents variously, mystical attributions and significations as understood within different worldviews. Through the application of interpretive discuss approach in relating relevant concepts of symbolism, the study elucidates on the symbolical, mythological, mystical and metaphorical denotations and attributions of chains, padlock and keys in line with Victor Turner's concept of operational, exegetical and positional meanings. In the end, we observe that the selected work by Idoko subsume deep and dense creative vision projecting deliberate effort in using art as a means of sharing cultural ideas, mystifying aesthetics, propelling curiosity, and mood/emotion intensity.
\end{abstract}

Keywords: Alex Idoko, art, Igbo, keys, metaphors, mystical, padlocks

\section{Introduction}

The phenomenon of art as a medium of human expression and communication remains a bourgeoning field of study in arts, humanities, psychology, medicine, and social sciences. In several reliable studies discussing art as a communication medium, there are plausible explanations illustrating how the utility of art extends beyond leisure and amusement in performing arts such as theatre arts and music. These studies variously suggest that art is one of the oldest medium of human expressions which play different vital roles in people's private and communal events all over the world. Thus, the acknowledgment of art as a means of communication is a universal phenomenon, even though its definition "is controversial in contemporary philosophy" and "whether art can be defined has also been a matter of controversy" (Adajian 2018: 1). However, Chijioke Onuora et al observe that "virtually all visible definitions of art and the counter arguments are in accord that art is an efficacious medium of communication,

This Open Access article is published under a Creative Commons Attribution Non-Commercial 4.0 International License (http://creativecommons.org/licenses/by-nc/4.0/), which permits non-commercial re-use, distribution, and reproduction in any medium, provided the original work is properly cited. For citation use the DOI. For commercial re-use, please contact editor@rupkatha.com. 
through which artists encode ideas, emotions, information, worldviews and knowledge for viewers' interpretation, reflection, appreciation, fulfilment, and enrichment" (2021: 2). The notion here is that art variously possess varying propensity to propel ideas, rouse or dowse mood intensity. Thus, these qualities of art variously help "to recalibrate, twist or re-aggregate people's worldviews, ideologies, and inclinations" and in some other instances, they help "to reinvent myths and legends, and to heal, revive, infuriate, or emotionalize people" (Onuora et al 2021: 2). This is because "artists have power", based on the efficacy of their creation which can act as emotional stimulus to music and theatre audience, thereby exerting significant influence on their concentration, articulation, perception, emotion, choice-making, and mood intensity (Gorman 2015: 4). What Gorman suggests is that an artist's influence revolves around "the power not just to create, but also to transform" because "for as long as art has existed, it has been sociallyengaged" (2015: 4). Therefore, it is plausible "to claim that art has values that transcend or reach beyond the so-called autonomously aesthetic" (Kostopoulos 2011: 523). The above view suggests that "art's utilities and functions, go way beyond the presentation of an aesthetic presence alone, but include projection of strong and efficacious ambiance, which encodes emotions, multiple layers and shades of information and knowledge, didacticism, and political realities" (Onuora et al 2021: 4).

Looking at an art as a plausible web of metaphorical significations in some instances, we can say that art can complicate the audience bid to interpret, by presenting more than literal attribution(s), hence in this complexity, it "extends the thread of recognition and understanding beyond what previously was seen and known" (Elderfield 2006: 44). Evidently, art is a universal common, with varied and similar production processes, attributions, and utilities. Therefore to achieve a valid interpretation of what an art communicates in specific contexts in performances; the music and theatre audience require relevant density of awareness about art in general, sufficient knowledge of different culture specific significations of objects, motifs, and colours that combine to form an art under consideration, and an extensive knowledge of the artists whose works they are interpreting (see Onuora et al 2021; Okpara et al 2020; Adajian 2018; Okada \& Ishibashi 2017; Goehr 2014; Demirel \& Altintas 2012; Haas 2011; Dean 2003; Tan 2000; Janaway 1998; Eagleton 1990; Levinson 1990; Dickie 1984; Weitz 1956).

In the fields of humanities and performance arts, studies discussing art as a medium and channel of expressing personal and collective worldviews in relation to ethnic, social, and religious inclinations, personal experiences and convictions abound. Our view is that worldview remains a major propelling factor that influences the kind of art an artist creates and worldview is a complex human conceptualization which is applied differently in different disciplines (Rousseau \& Billingham, 2018: 3). This is because in each discipline, scholars attempt "to emphasize a particularly relevant aspect, so that, for example, in management science, 'worldview' is typically taken to be about an individual or group's value system, while in theology, 'worldview' is often 
3 Creative Vision and Creative Arts: Significations and Metaphors of Keys in Alex Idoko's

Symbolist Arts

taken to be an individual's view about the existence and nature of God" (Rousseau \& Billingham, 2018: 3). However, worldview represents "the overall perspective from which one sees and interprets the world in all its diversity and complexity" and in many ways, worldview "functions as a 'map of reality' that people use to order their lives" (Rousseau and Billingham, 2018: 3).

Thus, our interpretation will attempt to read the symbolic items in the selected pyrography art of Alex Idoko to deepen our understanding of the worldview(s) underpinning the subsumed metaphorical meanings and paradigms, and to classify the underpinning worldviews as 'universal common(s)', or 'not universal common but multicultural' or 'culture specific'. More so, we are looking at how Idoko's art in figure 1, named 'Dissension' denotes 'humility' ambience and 'mystical' consciousness metaphorically to the music and theatre audience. In addition, this paper discusses how the creativity deployed by Idoko in the selected arts, help in creating scintillating aesthetics and dense messages that reflect paradigms, dynamics, and metaphors of Igbo ${ }^{1}$ culture specific inclinations and worldviews to the audience viewing it in a musical or theatrical performance. Conceptually, this study approaches the interpretations within the supposition that an art can differently and variously denote different things to different people in line with their different worldviews and inclinations. Therefore, a single piece of art can serve multiple purposes such as the projection of multiple meanings and emotional aggregation dynamics, which could be simultaneously diverse, similar, or specific to a group of beholders. More so, evident analytical understanding of what an art embodies, translates to an unfettered acceptance that the beauty of art revolves around its capacity to extend meanings and narratives to multiple metaphorical levels variously and differently.

\section{Creative Vision and Interpretive Methodology: Projection of 'Humility' in Symbolism}

The essential impetus for this study revolves around the following questions: can artistic creations depict narratives/texts signifying metaphorical suggestions that embody 'humility' and 'mysticism' at the same time, within a culture specific worldview in a musical or theatrical performance? For an artist such as Alex Idoko, creative vision in relation to the works in focus represents an ingenious deployment of functional sublime imagination and skills for the purpose of creating art that are effectively aesthetic and exceptional. Thus the way and manner the relevant symbolic items are brought together in the process of making an art defines an artist's creative vision, which can be assessed by analyzing the quality and quantity of subsumed artistic depth, concept(s) and context(s). To examine critically the density of the creative vision deployed in Idoko's application

\footnotetext{
${ }^{1}$ Igbo people are one of the three largest ethnic groups in Nigeria and Igbo is also the name of their native language. The eastern Nigeria predominantly and parts of south-south region of Nigeria are their aboriginal home.
} 
of symbolic items and patterns which we are saying can be read as a portrayal of 'humility', we shall start by establishing what 'humility' represents in this context.

Humility as a human reality represents different things to different individuals, depending on each individual's perspectives and ideological leaning, thus, humility has no definition that is based on consensus. In several academic works, scholars come up with debates, some presenting inquiries and contestations, some seeking or contributing illuminations and elucidations variously on whether "humility is good, or bad, about its effects, its precursors, and its relationship to various virtues, vices, and emotions, about how we might cultivate it (if we wanted to cultivate it at all), and about what previous thinkers thought about it [...]" (Collins \& McAnnally-Linz, 2020: 2). Hence, scholars variously present their descriptions of humility based on their inclinations and point of views. We see humility as an acquired way of life, variously applied by different individuals for purposes of attaining intended goals. More so, the shades and quality of humility each individual embodies as well as exhibits, largely are informed and influenced by a variety of variables and circumstances (such as nurture, nature, environment, vocation, and personal experiences), that subsisted or are subsisting within or around that individual. Our supposition trajectory is in line with the position of Stacey M. Floyd-Thomas who posits that "humility works more as spiritual disciplining, which is necessary for the increase of joy and love" and that it is "essential for the possibility of establishing cooperative life" (2020: 16).

Again, our position is that there are several ways of looking at the realities of humility and one of such ways is to interpret humility as a virtue which is thus "the practical attitudes and habits adopted" in obedience to specific principles, namely 'invisible dignity', 'quiet grace', and 'unshouted courage' (Cannon, 1996: 313). According to Jason Baehr "one familiar way of thinking about humility" is to view it as that which "comprises a certain attitude or orientation towards one's limitation" thus "a humble person is aware of, rather than oblivious to or in denial about, her limitations" (2020: 173). Also, our position in response to Baehr's view is that humility is a cultivated attribute which constitutes a subsisting ideology that helps an individual to appreciate the consequences of overreaching, the gains of not letting out all about self, and the profits of being able to achieve surprise and high degree of unpredictability in specific circumstances.

To produce a dependable and plausible explanation on what symbols in a given art denote, we believe it requires relevant diligent technique(s) as expressed in interpretive theories. Meanwhile, "to fully comprehend the quintessential characteristics of interpretivism as well as to better appreciate its uniqueness and usefulness, it is useful to begin by looking at its philosophical origins and then juxtaposing interpretivist theories with trajectories found in narrative paradigm" (Aniago 2018, p: 269). As April Vannini explains, "the expression interpretive theory, refers to a relatively large umbrella category that includes analytical perspectives and theories spanning the fields of communication, sociology, anthropology, education, cultural studies, political science, history, and the humanities" (2009, p: 557). Interpretive theories she observes are "ontological and 
5 Creative Vision and Creative Arts: Significations and Metaphors of Keys in Alex Idoko's Symbolist Arts

epistemological tools used in research concerned with understanding how individuals and groups create meaning in their everyday practices, communication, and lived experiences" (2009, p: 557). In addition, Vannini notes that adherents of the interpretivist theories are:

Scholars who are interested in the ways communities, cultures, or individuals, create meaning from their own actions, rituals, interactions, and experiences; scholars who wish to interpret local meanings by locating them into a broader historical, geographical, political, linguistic, ideological, economic, and cultural milieu; researchers who look at the meanings of texts and the codes and rules on which they rely to convey meaning; and theory and philosophy-oriented scholars who explore ideas of meaning and interpretation in and of themselves. (2009, p. 557)

The contribution Vannini accords with the methodological suggestions of Clifford Geertz and Victor Turner, as regards the need to seek diligently, dependable insider perspectives when carrying out interpretation of items and symbols. This approach will aid a critic's attempt to properly situate such analysis within specific era and location to reflect culture specific understandings as well as illumine relevant universal common.

To discuss 'humility' as metaphor in Idoko's 'Dissension' from the point-of-view of an audience who beholds it hanging on the walls at the background in a theatrical or music performance, we are adopting an interpretive approach as outlined in Clifford Geertz's concept of thick description. According to Geertz, thick description of culture specific worldviews and realities must reflect the interpretations of the people whose actions and practices one is analyzing, because that is what they profess to be the descriptions of their ways of life (1973: 15). The view here is that in attempt to adopt Geertz's thick description, critics require top quality insight through insider perspectives and definitions about the symbols they are interpreting. This explanation is line with the position of Victor Turner who suggests that "when we talk about the 'meaning' of a symbol, we must be careful to distinguish between at least three levels or fields of meaning" (1967: 50). Elaborating, Turner notes that the three fields of meaning are the level of indigenous interpretation (the exegetical meaning); the operational meaning; and the positional meaning (1967: 50). The exegetical meaning is given by the native commentary and it has three bases, namely; nominal (derives from associations with the name of the symbol), substantial (derives from natural and material properties of objects used as symbols) and artifactual (the result of purposive activity) (Turner, 1975: 152). The operational meaning of a symbol is equivalent to its use and to the effective qualities linked to the use - aggressive, sad, penitent, joyful, despair, and so on', whereas the positional meaning emanates from structural relationships that symbols have among themselves (Turner, 1967: 51). Emphasizing more on the suppositions separately made by Geertz and Turner on the need to seek the descriptions and meaning-making dimensions and perspectives which are in line with the worldview(s) of the people whose point-of-view(s) a critic 
intends to discuss, we can say that these suppositions are plausible and essential because symbolic meaning(s) of items or things in a good number of instances differ from one community to another.

To elaborate on the conscious application of items as symbols in art which is referred as symbolism, we can say that this conscious act is driven by the creative vision of the artist to embed specific metaphorical ideas and significations which will add to the overall narrative allure and magnitude. Meanwhile, symbolism is describable as an artistic style, a system of signs, and its study is referred to as symbology. It was coined in 1886 by French critic Jean Moréas primarily to describe Stéphane Mallarmé and Paul Verlaine poetry as representation of ideas beyond the supposed literal connotations. Through the course of art history, symbolism as a late nineteenthcentury art movement of French, Russian and Belgian origin in poetry and other arts, in many ways was propelled by increased imaginative representation driven by symbols that embed intended metaphorical attributions (see Hyland and Bateman, 2011; Müller-Brockmann, 1971).

In its application in visual and performance arts, symbolism represents attempts at depiction of ideas through symbols to project metaphorical significations and meanings. According to Raymond Firth symbols are "instruments of expression, of communication, of knowledge and of control" and devices for creation of abstractions, however, meaning is required ultimately (1973: 77). More so, symbolism can be described as the creative incorporation of specific symbols in arts to communicate specific or intended message(s) to the beholder(s). However, in some cases, such as in performance arts, symbolism may appear to be unrecognizable, incongruent, or abstruse at varying degrees depending on who is the beholder. Thus, the significations of the symbolic items may be so puzzling that a beholder may require the help of another individual who is knowledgeable in that regard to receive plausible explanation and interpretation in a bid to appreciate sufficiently the intended message(s). The notion here is that symbolism represents the understanding that symbolic items may likely denote different things to different individuals during a theatrical or music performance.

\section{Key as a Symbol}

In her presentation of exegetical meaning, Pernille Pantmann notes that "in several cultures, including the Roman, a key symbolises 'being the Chosen one' as well as being an expression of the possession of leadership qualities and being a decision maker; in brief this means power and responsibility" (2011: 80). Espousing Pantmann notes that:

Women who were buried with keys could, therefore, by virtue of their abilities and actions, have been chosen for special tasks in society - possibly tasks which they 
7 Creative Vision and Creative Arts: Significations and Metaphors of Keys in Alex Idoko's Symbolist Arts

performed alongside their traditional tasks. But these were actions which were important enough to be marked at their burial in the form of the key. (2011: 80)

In addition, Pantmann observes that in line with the findings in graves containing keys on Zealand which spans the entire Viking age "the theory of the key as a symbol of the mistress of the household, based on documentary source, has won greatest resonance and has, with time, become an accepted truth" (2011: 76). Thus, several researchers are of the view that women who are buried with items such as keys could have played a part in the execution of cultic practices, which again are within exegetical meaning (Callmer 1990, 683; Fabech 1998, 151; Price 2002, 265; Staecker 2003, 472). More so, the contribution of Pantmann that in some legend and folklore, three keys are often used to symbolize a like number of secret chambers full of precious objects and they are symbolic representations of initiation and knowledge are within exegetical as well as positional meanings. It is exegetical because a particular culture embed the meaning and it is acknowledged by them, however it is positional because the idea that "the first key, of silver, concerns what can be revealed by psychological understanding; the second is made of gold, and pertains to philosophical wisdom; the third and last, of diamond, confers the power to act" is in many ways mystical and illusionary (Pantmann 2011; Loeffler-Delachaux, 1949).

The description of key as that which sometimes refers to the threshold of the unconscious and as an attribute, whereby key pertains to several mythic characters, including Hecate (Jung, 1953; Jung, 1958), the suggestion that the emblem formed by two keys, sometimes placed over a heart, relates to Janus, and that the conjunction of the symbols of the male dove and the key signifies the spirit opening the gates of heaven (Bayley, 1951), are all within the positional meaning sphere and paradigm. Key is symbolic of mystery or enigma, or of a task to be performed, and the means of carrying it out, and clearly there is a morphological relationship between the key and the Nem Ankh sign (or 'Eternal Life') - the anserated cross of the (Cirlot, 1971: 167). In line with Egyptian mythology, "Egyptian gods are sometimes shown holding the anserated cross by the top as if it were a key, especially in ceremonies concerning the dead" however, that "it is the keys that derive from the anserated cross, the archetype of the key of Eternal Life that opens up the gates of death on to immortality" (Cirlot, 1971: 168). The mystical concept in the above contribution relates with the quote in the Bible in Revelation ix, verses 1-10: "And the fifth angel sounded, and I saw a star fall from heaven unto the earth: and to him was given the key of the bottomless pit" (Cirlot, 1971: 190). Also, still on mystical significations of key, scholars observe that in certain rite and rituals, the neophyte is required to divest himself of his 'metals' - coins, keys, trinkets because they are symbolic of his habits, prejudices and characteristics, etc. (Blavatsky, 1888). Furthermore, certain Islamic rites, there are mystical connotations whereby rituals are patterned in quinary: there are five religious duties, five keys to secret knowledge, five daily prayers and a solemn oath is repeated five times (Cola, 1949). Again, another illustration suggests the mystical 
connotation of key as the great priestess, the second enigma of the Tarot, which represents Isis as the goddess of the night, and she is seated, holding a half-opened book in her right hand, and two keys in her left. One of the keys is golden (signifying the sun, the word, or reason), and the other key, silver signifies (the moon or imagination) (Cirlot, 1971: 133). Her throne is situated between two columns - being two in number, they are an allegory denoting the feminine principle - which are in fact the columns called Jachin and Boaz in the Temple of Solomon, joined together by the veil which covers the entrance to the sanctuary (Cirlot, 1971: 133). The examples presented by Cola, Blavastsky, and Cirlot respectively denote mystical attributions linked to keys by people in different climes.

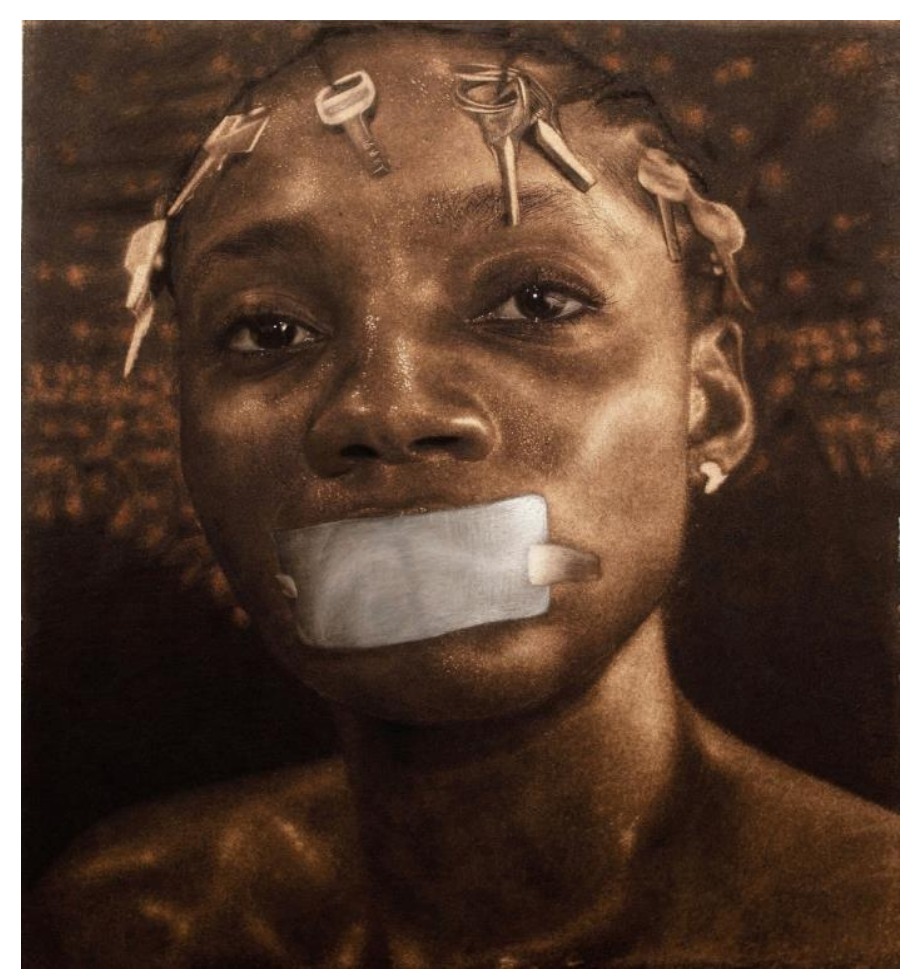

Figure 1 'Dissension', 2019 by Alext Idoko, Pyrograhpy art created with razorblade, sandpaper and charcoal on wood, size ' 35 x 43' inches $-12 \mathrm{~mm}$ thick

\section{Interpretations of Key in Idoko's Art}

We can see in figure 1, a girl's head, face, neck and the upper portions of her uncovered shoulders, and she falls within the ages of 14-25, describable as the period of intense beginning of dense intellectual exuberance and search. Her dark-brownish face, body hue, and a distinct broad nose, depict her as a girl from African descent. Idoko presents her in a telling countenance and mood intensity, as well as in an appearance punctuated with symbolic items.

Her appearance suggests 'humility' and 'mysticism'. This is because her eyes which are suggestively concentrating intensely and intently ahead of her can be described as ominous and 
9 Creative Vision and Creative Arts: Significations and Metaphors of Keys in Alex Idoko's Symbolist Arts

at the same time devoid of anxiety. The intensity of her gaze and focus suggest active consciousness. Thus, her facial expression which is apparently devoid of contortions, suggests a high degree of emotion containment and palpable consciousness alertness. Her hair is decorated with Afro-style simple low cost flat-on-the-skull braids. The tips of the braids which extend round her head are attached to keys aesthetically as ornaments and they symbolically represent multiple 'access means'. The sealed mouth effectively suggests that the girl will temporary not speak. The expression 'temporary' is applied because the masking tape is more symbolic than permanent. Thus, the linking of the symbolic supposition of the contexts of her sealed mouth, her alert eyes, and the keys that are ornamentally place at tips of her braids, we can say that she possesses knowledge and crucial information, which she is not at liberty to disclose orally, though temporary. In a bid to project the desired countenance and mood, Idoko presents the girl with teary eyes, and a piercingly intense concentration focus, which she casts towards her direct distant view point. Her demure embodies a sense of humility because the quality of calmness despite her alertness as indicated through her eyes suggests awareness, and the material used in sealing her mouth which does not seal it permanently, clearly indicate that she can remove it and speak, but she is letting it on.

The appearance of the girl can be described as either 'submissive humility' or 'tacit humility'. Submissive humility suggests that the girl in the frame is not at liberty to disclose may be because she is prohibited by strict socio-cultural rules. Also, her countenance can be described as 'tacit humility' because it may be that she chooses not to disclose based on her personal reasons. The first trajectory is to say that the girl in the frame is undergoing a ritual process, prayer and supplication hence the countenance suggesting humility. In this regard, the keys firmly attached to the braids around the head are symbolic suggestion that accesses to openings such as good luck, knowledge and mystical illumination may be part of her supplication ritual. Thus, within mystical purview, probably such ritual is done to attain mystical powers with which the subject can use to access further illumination and acceptance to spiritual realms. The second trajectory is that since keys serves as means of unlocking a lock, the girl signify someone who has power to give access. The focused and patient eyes suggest that the girl is alert and aware; hence, the sealed mouth may not hold her back perpetually.

The interpretations we provided above are generated from respondents who were part of the spectators during a dance drama performance which took place at the in the University of Nigeria, Nsukka. We experimented by framing Alex Idoko's art 'Dissension' and then placed it on the wall of the backdrop facing the spectators directly before the dance as decorative images for the purposes of finding out their interpretations of images in relation to the performance. Thus, the creative vision in Idoko's depiction revolves around the symbolic items he employed in this art which fall within the operational meaning according to the respondents' responses we 
gathered. We also consulted and interviewed some mystics and spiritualists practicing in line with African traditional religion, pastors and priests of Christian denominations, and lay men and women. Their responses give credence to the idea that the shades and nuances of art interpretations in many ways are influenced by a number of factors and variables, such the quality of an individual's knowledge of art in general, a beholder's ability to interpret images and renderings in the art and relate them to a specific locale, and a sound of artists and their works. The idea is that the application of dense symbols when creatively applied in art, help in generating specific atmospheres that enrich its aesthetics. Thus, artistic symbols in many ways act as complimentary narrative tools that elevate and define the message from the artist, which can help to generate efficacious consciousness and mood aggregation in the viewers. This affirms that an art is capable of propelling similar as well as dissimilar significations and emotions to a group of beholders because of the probable similarity or dissimilarity of their subsisting socio-cultural inclinations, worldviews, experiences, cognition/knowledge densities and emotional bents.

However, in all the responses we gathered there are clear indication that Idoko's 'Dissension' did not yield culture specific interpretations. The respondents applied the operational meaning of key which a tool for unlocking a lock to frame their interpretations which in some cases tended to tilt towards metaphysical. We also noticed that 'Dissension' created divergent interpretations which in their own right are plausible. Again, the spectators in the dance drama continually attempted to link the narrative presented in 'Dissension' with the theme of the performance, which added to their curiosity and concentration. Therefore, the placing of 'Dissension' on the wall which the spectators continued to interpret to find its link to the dance drama indicates that arts with significant symbolic items when properly selected and placed on the backdrop in dance drama performance can help in accentuating the narrative as well as increase curiosity of the spectators positively.

\section{Conclusion}

Our analysis of the portrayals of keys accords with the view expressed by some scholars who have researched substantially on symbolisms of key. Regardless of the fact that, art variously possesses the propensity to propel efficacious affectations in the beholder's subconscious, such can only occur if there is a stream consciousness from the art to the beholder. This manifestation is capable of altering the beholder's inclination and worldview positively or negatively depending on the point-of-view of his/her judgement. On creative vision, we observe that the symbolic items in Idoko's art present both operational and positional meanings. The study notes that the following suppositions about art enjoys unambiguous acknowledgment; that the creation and study of art are both universal commons which transverse race, gender, age, social status, ideological 
inclinations and locale specific differences; that different forms of art exist in every corner of the world; that art forms are widely viewed as mediums of self expressions; that arts are reflections of life and societal realities from diverse and similar perspectives; that these reflections emanate from various inspirational sources, and that art produces diverse as well as similar significations, attributions, meanings and emotions to the viewers.

\section{References}

Adajian, T. (2018). 'The definition of art' Stanford encyclopaedia of philosophy. Stanford: Stanford University.

Aniago, E. \& Igbonekwu, J. (2018). 'Social construction of reality in Chukwuemeka Ike's The Potter's Wheet. Focus on didacticism, attribution and interpretive community' Ikoro: Journal of Contemporary African Studies, 1 \& 2: $267-279$.

Baehr, J. (2020). 'Defining Humility: The Scope of Humility' The Joy of Humility: The Beginning and End of the Virtues, Collins, D., McAnnally-Linz, R., \& Rosa, E. V. (eds), Texas Baylor University Press, 173 - 189.

Bayley, H. ([1912]1951). The Lost Language of Symbolism. London: Barnes \& Noble Blavatsky, H. P. (1888). The Secret Doctrine. New York: Theosophical Pub. Co.

Callmer, J. (1990). 'Review of M. Muller-Wille, Das Wikingerzeitliche Graberfeld von Thumby-Bienebek' (Kr. Rendsburg-Eckernforde). Germania, 68(2): 681 - 683.

Cannon, K. G. (1996). 'Womanist virtue' Dictionary of Feminist Theologies. Russell, L. M. \& Clarkson, J. S. (eds). Louisville: Westminster John Knox.

Cirlot, J. E. (1971). A Dictionary of Symbols (2nd Edition). London: Routledge \& Kegan Paul Ltd

Cola, A. J. (1949). Moroccan Tattoos and Amulets. Madrid: CSIC, Institute of African Studies

Collins, D. \& McAnnally-Linz, R. (2020). 'Introduction: Contesting Humility' The Joy of Humility: The Beginning and End of the Virtues, Collins, D., McAnnally-Linz, R., \& Rosa, E. V. (eds), Texas Baylor University Press, 1 - 8.

Dean, J. (2003). 'The nature of concepts and the definition of art' Journal of aesthetics and art criticism, 61: $29-35$.

Demirel, I. N. \& Altintas, O. (2012). 'Relationship between art and politics' Procedia - Social and Behavioural Sciences, 51: $444-448$.

Dickie, G. (1984). The art circle. New York: Haven Publications.

Eagleton, T. (1990). The ideology of the aesthetic. London: Basil Blackwell.

Fabech, C. (1998). 'Kult og samfund i yngre jernalder - Ravlaunda som eksempel' In: L. Larsson \& B. Hardh (eds): Centrala Platser - Centaler Fragor. Samhallsstrukturen under Jarnalderen. Acta archaeologica Lundensia series' 8(28): 147 - 163.

Firth, R. (1973). Symbols: Public and private. Ithaca: Cornell Univ. Press

Fish, S. (2004). 'Rhetoric, phenomenology, and reader response'. Rivkin, J. \& Ryan, M. (eds) Literary Theory. An Anthology. Oxford: Blackwell Publishing, 217 - 221.

Floyd-Thomas, S. M. (2020). 'Oppressive Humility: A Womanist View of Humility, Flourishing, and the Secret of Joy' The Joy of Humility: The Beginning and End of the Virtues, Collins, D., McAnnally-Linz, R., \& Rosa, E. V. (eds), Texas Baylor University Press, $13-32$.

Geertz, C. (1973). The interpretation of cultures. New York: Basic Books.

Goehr, L. (2014). 'Art and politics' The Oxford handbook of aesthetics. Levinson, J. (ed), Oxford: Oxford University Press. 
Haas, S. (2011). Can art influence political policy on the environment: $A$ case study examining Rolf Groven's eco-art, MPhil Thesis, Centre for Development \& the Environment, University of Oslo, Blindern, Norway.

Hyland, A. \& Bateman, S. (2011). Symbol. London: Laurence King.

Janaway, C. (1998). Images of excellence: Plato's critique of the arts. Oxford: Oxford University Press.

Jung, C. G. (1953). Psychology and Alchemy (Collected Works, 12) London: Pantheon Books

Jung, C. G. (1956). Symbols of Transformation (Collected Works, 5) London: Routledge

Levinson, J. (1990). Music, art, and metaphysics. Ithaca: Cornell University Press.

Lévi-Strauss, C. (1966). The savage mind. London: Weidenfeld and Nicolson.

Loeffler-Delachaux, M. (1949). Le Symbolisme des contes de Fées. Paris: L'Arche

Müller-Brockmann, J. (1971). A history of visual communication. Teufen: Verlag A. Niggli.

Okada, T. \& Ishibashi, K. (2017). 'Imitation, inspiration, and creation: Cognitive process of creative drawing by copying others' artworks', Cognitive science. 41(7): $1804-1837$.

Okpara, C., Aniago, E., \& Okpara, T. F. (2020). 'Metaphor and melancholy consciousness: enduring efficacy and universal common in Obiora Udechukwu's eight paintings' Rupkatha Journal on Interdisciplinary Studies in Humanities, 12(6): 1 - 15.

Onuora, C., Ikwuemesi, K., Okpara, C. \& Aniago, E. (2021). 'Reflections of society in art: Contributions of Michael Soi's politics paintings to socio-political debates in Africa' Rupkatha Journal on Interdisciplinary Studies in Humanities, (13)1: 1 - 16.

Pantmann, P. (2011). 'The Symbolism of Keys in Female graves on Zealand during the Viking Age' In: The Iron Age on Zealand: Status and Perspectives, Linda Boye (ed), Copenhagen: the Royal Society of Northern Antiquaries

Price, N. (2002). The Viking Way - Religion and war in Late Iron Age Scandinavia. AUN 31, Dept. of Archaeology and Ancient History, Uppsala University, Uppsala

Staecker, J. (2003). 'The Cross goes North. Christian Symbols and Scandinavian Women. I. M. Carver (ed.): The Cross goes North. Processes of Coversion in Northern Europe AD 300-1300, $463-482$.

Tan, E. S. (2000). 'Emotion, art \& the humanities' Handbook of emotions, 2nd Ed, Lewis, M. \& HavilandJones, J. M. (Eds.), New York: Guilford Press, $116-136$.

Turner, V. (1968). The drums of affliction. Oxford: Clarendon Press.

Turner, V. (1967). The forest of symbols. Ithaca, N.Y.: Cornell University Press.

Turner, V. (1969). The ritual process. London: Routledge \& Kegan Paul.

Turner, V. (1975). 'Symbolic studies' Annual Review of Anthropology, (4): 145 - 161.

Vannini, A. (2009). 'Interpretive theory' Encyclopaedia of communication theory, Littlejohn, S. W., \& Foss, K. A., (eds) Los Angeles: SAGE Publications, Inc., 557 - 562.

Weitz, M. (1956). 'The role of theory in aesthetics' Journal of aesthetics and art criticism. 15: 27 - 35. 